\title{
Susceptibilidade a erosão na bacia hidrográfica do córrego Guariroba, Campo Grande, Mato Grosso do Sul
}

\author{
Viviane Capoane \\ Universidade Estadual de Mato Grosso do Sul, Mato Grosso do Sul, Campo Grande, 79115-898, Brasil. \\ capoane@gmail.com
}

Recebido: 6 abril 2019 / Aceito: 1 maio 2019 / Publicado online: 27 maio 2019

\begin{abstract}
Resumo
A captação de água para o abastecimento humano na cidade de Campo Grande é feita em mananciais superficiais e aquíferos, dos quais o reservatório Guariroba é a principal fonte superficial. O objetivo deste estudo foi avaliar a susceptibilidade a erosão e o uso e cobertura da terra na bacia hidrográfica do Córrego do Guariroba, a fim de subsidiar a gestão ambiental. Atributos topográficos extraídos de um modelo digital de elevação obtido por fotogrametria foram utilizados para avaliar a susceptibilidade a erosão. O índice de vegetação por diferença normalizada (NDVI), obtida de imagens Sentinel 2B, foi usado para a análise do uso e cobertura da terra. Os atributos topográficos mostraram os locais mais susceptíveis ao desenvolvimento dos processos erosivos, que, encontram-se ao longo dos cursos d'água, nas cabeceiras de drenagem e em vertentes côncavas convergentes. Nesses locais os fluxos superficiais têm maior energia, consequentemente, o poder erosivo é maior, aumentando a susceptibilidade a perda de sedimento e poluentes adsorvidos. A vegetação natural remanescente encontra-se ao longo dos cursos d'água e em pequenos fragmentos. Plantios de eucalipto avançam em áreas de pastagens formando mosaicos na paisagem. Os mapas gerados podem ser utilizados pelos gestores na identificação das áreas prioritárias para recuperação ambiental.
\end{abstract}

Palavras-chave: Assoreamento, degradação ambiental, índices topográficos, reservatório.

\section{Susceptibility to erosion in the Córrego Guariroba watershed, Campo Grande, Mato Grosso do Sul}

\begin{abstract}
Water capture for domestic use for the city of Campo Grande consists of superficial springs and aquifers, of which the Guariroba reservoir is the main surface source. This study evaluated the susceptibility to erosion, and land use and cover in the Guariroba Stream watershed, in order to assist environmental management. Topographic attributes extracted from a digital elevation model obtained by photogrammetry were used to evaluate susceptibility to erosion. The normalized difference vegetation index (NDVI), obtained from Sentinel 2B images, was used for land use and land cover analysis. The topo-graphic attributes showed the most susceptible sites for the development of erosive processes, which are found along watercourses, drainage headwaters and convergent concave slopes. Here, the surface water flows have higher energy, consequently, their erosive power is greater, increasing the susceptibility to loss of sediment and adsorbed pollutants. The remaining natural vegetation is found in small fragments along the water course. Eucalyptus plantations encroach pasture areas, forming mosaics in the landscape. The generated maps can be used by administrators for the identification of priority areas for environmental recovery.
\end{abstract}

Keywords: Sedimentation, environmental degradation, topographic indexes, reservoir.

\section{Introdução}

No passado recente, os seres humanos pensavam na água doce como uma constante. Às vezes havia seca, e às vezes havia inundação, mas os níveis de água sempre voltavam ao normal. Assim, foram construídas barragens e reservatórios, muitas de enorme infraestrutura, pois pensava-se que estas seriam capazes de suprir a demanda caso houvesse qualquer variação de curto prazo, presumindo que os períodos de seca terminariam e as bacias hidrográficas se reabasteceriam (Schlanger, 2018). No entanto, face ao manejo inadequado dos recursos naturais, das mudanças climáticas e, pela crescente demanda humana por água de uma população que, segundo Hooke et al. (2012), em 2050 ultrapassará a marca de nove bilhões, reservatórios estão se tornando 'dinossauros' e, a tendência é que não sejam mais construídas barragens, pois não haverá água para reabastecer os reservatórios (EA UK, 2018).

Na cidade de Campo Grande, Mato Grosso do Sul, cerca de $50 \%$ do abastecimento de água é oriundo de reservatórios localizados nas Áreas de Proteção Ambiental (APA) dos Mananciais dos Córregos Guariroba e Lajeado, sendo a mais relevante a APA dos Mananciais do Córrego Guariroba, 
principal fonte de abastecimento de água superficial da cidade. Estas APAs foram criadas em decorrência da necessidade que o município apresentava, na época da construção, de recuperar e conservar a principal fonte de água doce no município (SEMADUR, 2008). Porém as propriedades inseridas nas bacias hidrográficas não estão respeitando o Plano de Manejo, deixando que ocorram impactos negativos na área (Camargo, C.M.J., Camargo, L.J.J. e Oliveira, A.K.M., 2010), o que pode colocar em risco o abastecimento de água da cidade em um futuro próximo.

Considerando que o Reservatório do Guariroba abriga a principal fonte de água potável superficial do município de Campo Grande, o objetivo deste estudo foi avaliar a susceptibilidade a erosão e o uso e cobertura da terra na Área de Proteção Ambiental dos Mananciais do Córrego do Guariroba, a fim de subsidiar o planejamento e a gestão ambiental.

\section{Material e Métodos}

\section{Caracterização da área de estudo}

A bacia hidrográfica $(\mathrm{BH})$ do Córrego Guariroba possui 37.255 ha e localiza-se integralmente no município de Campo Grande, Mato Grosso do Sul, a leste da sede do município (Figura 1).

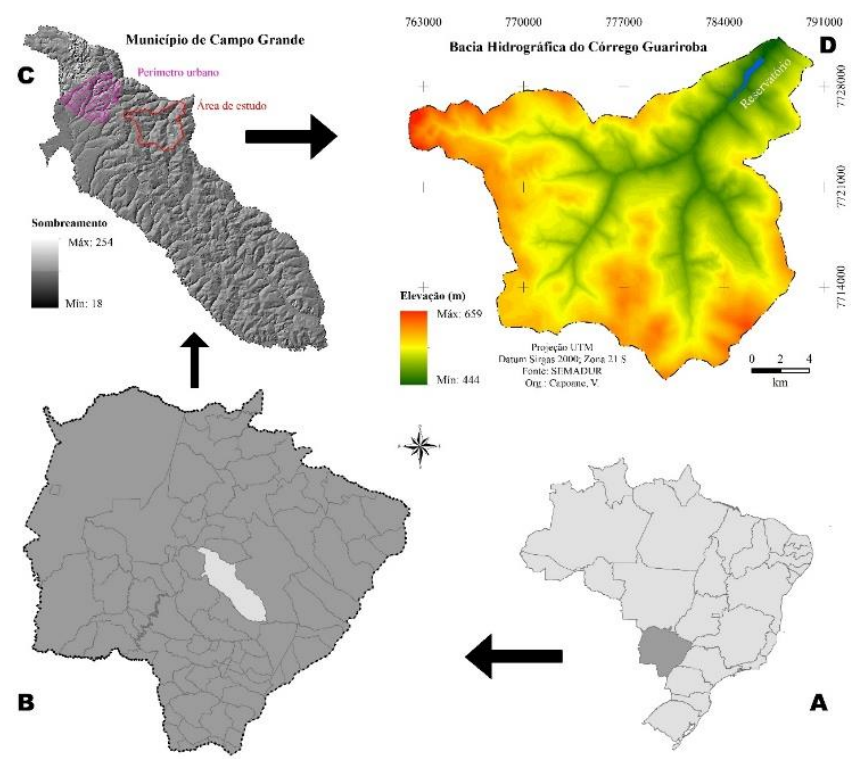

Figura 1. Brasil com destaque para o Estado de Mato Grosso do Sul (A); Estado do Mato Grosso do Sul com destaque para o município de Campo Grande (B); Localização da bacia hidrográfica do Córrego Guariroba no município (C) e; Bacia hidrográfica do Córrego Guariroba (D).

O território da APA é composto por formações sedimentares, unidades Caiuá e Cobertura Detrito-Laterítica Neogênica e, rochas ígneas da Formação Serra Geral (Araújo et al., 1982). A formação Serra Geral dá origem a solos com textura média e argilosa como Latossolo Vermelho e Latossolo Vermelho-Amarelo, que estão associados aos relevos colinosos e aplanados, que predominam na bacia hidrográfica. As rochas sedimentares dão origem a solos arenosos ou areno-argilosos, variando a fração de finos em consequência da composição dos arenitos. A classe Neossolos Quartzarênicos, predomina na bacia hidrográfica. Ocorrem ainda, associados às planícies fluviais e aos depósitos de várzea, tipos pedológicos classificados como Neossolos Quartzarênicos Hidromórficos e, eventualmente, Neossolos Flúvicos (SEMADUR, 2008).

A bacia hidrográfica apresenta drenagem com padrão dendrítico, paralela ao rio Paraná e orientando-se de sudoeste para nordeste; tem como afluentes mais importantes, o córrego Rondinha e os córregos Galho Quebrado, Desbarrancado e Saltinho (Oliveira, A.K., Fernandes, V., Pirajá, R.V. e Silva, M.H.S., 2017). No contexto regional, o Córrego Guariroba é afluente do Ribeirão Botas, que por sua vez é afluente do Rio Pardo, importante afluente do Rio Paraná.

O clima da região é o monçônico (Am), conforme a classificação climática de Köppen (Alvares et al., 2014). Em 2018 a temperatura média anual da região foi de $24{ }^{\circ} \mathrm{C}$ e a precipitação anual de $1.316 \mathrm{~mm}$ (CEMTEC MS, 2018), sendo que as chuvas se concentram entre outubro e março.

A vegetação da região encontra-se no bioma Cerrado, com a presença dos seguintes tipos fitofisionômicos: cerrado stricto sensu, cerradão, vereda, buritizal, formações ripárias e áreas de pastagens (Oliveira et al., 2017). O território da BH é caracterizado essencialmente pela ocupação rural através da criação extensiva de gado (Camargo et al., 2010) e, mais recentemente com a inserção da silvicultura (Oliveira et al., 2017).

\section{Sistema Guariroba}

A captação de água para o abastecimento de Campo Grande é feita de duas formas: a primeira, superficial, nos córregos Guariroba, área de estudo do presente trabalho, e Lajeado; já a segunda é de aquíferos - Grupo Bauru (livre), Formação Serra Geral (fissural) e Guarani (confinado). A BH do Córrego Guariroba é de suma importância, pois é a principal fonte superficial de abastecimento de água para a cidade.

A implantação do Sistema Guariroba deu-se entre 1982 e 1987 e, conforme Oliveira et al. (2017), devido à perda significativa de vegetação nativa nesse período, a fim de preservar os recursos hídricos da região, em 1995, foi criada a Área de Proteção Ambiental dos Mananciais do Córrego Guariroba.

Conforme o Art. 15. da Lei 9.985/2000 (Brasil,2000) que institui o Sistema Nacional de Unidades de Conservação da Natureza - SNUC, a Área de Proteção Ambiental é uma área em geral extensa, com um certo grau de ocupação humana, dotada de atributos abióticos, bióticos, estéticos ou culturais especialmente importantes para a qualidade de vida e o bemestar das populações humanas, e tem como objetivos básicos proteger a diversidade biológica, disciplinar o processo de ocupação e assegurar a sustentabilidade do uso dos recursos naturais. Segundo Silva (2010), são espaços protegidos, mas a intensidade da proteção ambiental é menor do que a que se aplica nas Unidades de Proteção Integral, pois, ao contrário destas, permitem o uso direto dos seus recursos naturais. Seu objetivo básico é compatibilizar a conservação da natureza com os usos antrópicos. 


\section{Extração dos atributos topográficos}

A base para a extração dos atributos topográficos é um Modelo Digital de Elevação (MDE) hidrologicamente consistente da bacia hidrográfica. O MDE utilizado no presente trabalho foi gerado no programa ArcGIS 10.3 a partir de um levantamento aerofotogramétrico (curvas de nível com equidistância de cinco metros e pontos cotados) do município de Campo Grande, realizado pela Secretaria Municipal de Meio Ambiente e Desenvolvimento Urbano (SEMADUR). O método de interpolação utilizado para a geração do MDE foi o Topogrid, desenvolvido para estudos hidrológicos (Hutchinson, 1989). Para Jenson \& Dominique (1988), este método permite congregar tanto as feições hidrográficas como a remoção de dados espúrios relativos a pontos de depressões. A resolução espacial selecionada para a interpolação e geração do MDE foi a de cinco metros.

A partir do MDE gerado, o mesmo foi convertido para o formato txt e, no programa SAGAGIS 7.0. (Conrad et al., 2015), foram determinadas a declividade, hipsometria, o Índice Topográfico de Umidade (ITU), Índice Topográfico de Potência de Escoamento (ITPE) e, Índice Topográfico de Capacidade de Transporte de Sedimento (ITCTS) ou fator topográfico LS (Slope Length), para a BH do Córrego Guariroba.

O fator ambiental declividade foi separado em classes utilizando os intervalos propostos por Lepsch (1991): 0-2\% (relevo plano - terraços), 2-5\% (relevo suave ondulado colinas), 5 a $10 \%$ (relevo ondulado - morros e morrotes), 10$15 \%$ (relevo muito inclinado - morros e morrotes), 15 a $45 \%$ (relevo fortemente ondulado - morros e serras), 45 a $100 \%$ (relevo montanhoso - montanhas e serras) e $>100 \%$ (relevo escarpado - serras e escarpas).

O ITCTS é calculado com base no fator topográfico LS da Equação Universal de Perda de Solo, porém com a inserção da influência da forma das encostas - área especifica (As) $(\mathrm{LS}=($ As $/ 22,13) \mathrm{m})(\tan \beta / 0,0896) n$. O uso do ITCTS permite a identificação na paisagem dos locais mais propensos ao desenvolvimento de processos erosivos (Minella et al., 2010).

O ITU foi desenvolvido por Burt e Butcher (1935) a fim de possibilitar a simulação das áreas de variável afluência (zonas saturadas) que, em BHs estão associadas às regiões de linha de fluxo convergente e baixas declividades. Este índice é definido pelo logaritmo natural da razão entre a área de contribuição específica e a tangente do ângulo da declividade $(\mathrm{ITU}=\ln (\mathrm{As} / \tan \beta))$. A equação mostra que o ITU é função apenas de $\beta$, assim é adicionada a seguinte restrição: $0^{\circ}<\beta<$ $90^{\circ}$, pois se $\beta=0, \tan \beta=0$ e $1 / \tan \beta$ é infinito e, se $\beta=90^{\circ}, 1$ $/ \tan 90=0, \ln 0$ é infinito.

O ITPE é um atributo topográfico secundário que descreve o potencial da topografia para concentrar grandes quantidades de água superficial, promovendo o entalhe (Capoane, 2015). Ele é derivado da área de contribuição específica do fluxo acumulado e da declividade a partir de um MDE, sendo formulado como: ITPE $=$ As $x \tan \beta$. A determinação da energia erosiva superficial dá-se com base no pressuposto de que o fluxo acumulado e declive são proporcionais ao potencial de arraste do sedimento. Assim, destaca grandes áreas e encostas íngremes onde o poder erosivo do escoamento superficial será mais elevado (Wilson \& Gallant, 2000).

\section{Uso e cobertura da terra}

Índice de Vegetação por Diferença Normalizada (NDVI = (Infra Vermelho - Vermelho) / (Infra Vermelho + Vermelho), é um dos indicadores numéricos mais amplamente utilizados que usa as bandas visível e do infravermelho próximo do espectro eletromagnético, e é utilizado para analisar imagens de sensoriamento remoto e avaliar se o alvo contém vegetação verde viva ou não. Este índice também vem sendo utilizado de forma significativa, para detectar mudanças na cobertura da terra causadas por atividades humanas, como construções, supressão da vegetação florestal, bem como analisar as mudanças espaço-temporais da cobertura vegetal.

Visando obter uma caracterização visual do uso e cobertura da terra na bacia hidrográfica do Córrego Guariroba foi gerado o NDVI utilizando imagens do satélite Sentinel 2B com resolução espacial de 10 metros (bandas B4 (RED) e B8 (NIR)) do ano de 2018, nas estações de verão (23/02/18) e inverno (11/09/18). As imagens são disponibilizadas gratuitamente pela Agência Espacial Europeia (https://scihub.copernicus.eu/dhus/\#/home).

\section{Resultados e Discussão}

As cotas altimétricas da $\mathrm{BH}$ do Córrego Guariroba variam de 444 a 659 metros sendo a amplitude de 215 metros (Figura 1). O declive máximo encontrado foi $29,1 \%$, e a classe de relevo predominante, a suave ondulado - colinas (declive entre 2 e $5 \%$ ) com $56,6 \%$ da área da $\mathrm{BH}$; seguido do relevo ondulado - morros e morrotes (declive entre 5 e $10 \%$ ) com $23,2 \%$; relevo plano - terraços (declive entre $0-2 \%$ ) com $18,8 \%$; relevo muito inclinado (declive entre 10 e 15\%) com 1,8\% e; relevo fortemente ondulado (declive entre 15 e $45 \%$ ) com $0,1 \%$ da área da bacia hidrográfica (Figura 2A).

$O$ índice topográfico de capacidade de transporte de sedimento variou de 0 a 11,4 (Figura 2B), com média de 0,39 e desvio padrão de 0,32 . A cor azul representa predominantemente áreas caracterizadas por relevo plano com declives inferiores a 5\%, localizadas principalmente nos inteflúvios. Na transição das cores azul e amarela, predominam declives entre 5 e $10 \%$. A cor vermelha representa as áreas mais declivosas da $\mathrm{BH}$. A transição de cores mostra que quanto maior os valores do ITCTS, maior será a energia dos fluxos superficiais, consequentemente, maior será o poder erosivo, aumentando assim a susceptibilidade a perda de sedimento e poluentes, que além do assoreamento do reservatório do Guariroba e diminuição do potencial de armazenamento de água, podem causar a degradação da qualidade da água dos rios e do reservatório, que é a principal fonte superficial de abastecimento de água da cidade de Campo Grande.

O índice topográfico de umidade variou de 2 a 12 (Figura $3 \mathrm{~A}$ ), com média de 5,4 e desvio padrão de 1,1. A cor azul escura representa as áreas com maior potencial de saturação hídrica, ou seja, áreas com maior potencial de acúmulo de água e geração de escoamento superficial, típico de solos hidromórficos. Na BH essas áreas estão localizadas ao longo dos cursos d'água e nas cabeceiras de drenagem. As cores intermediárias representam pendentes de curvatura 
convergente, locais onde os fluxos tendem a se concentrar, aumentando a umidade do solo. Estas áreas estão presentes, principalmente, no terço inferior das encostas e nos interflúvios mais extensos. A cor azul clara indica locais com baixa umidade do solo e estão presentes em vertentes divergentes, em locais com declive acentuado e, nos interflúvios de pequena extensão.
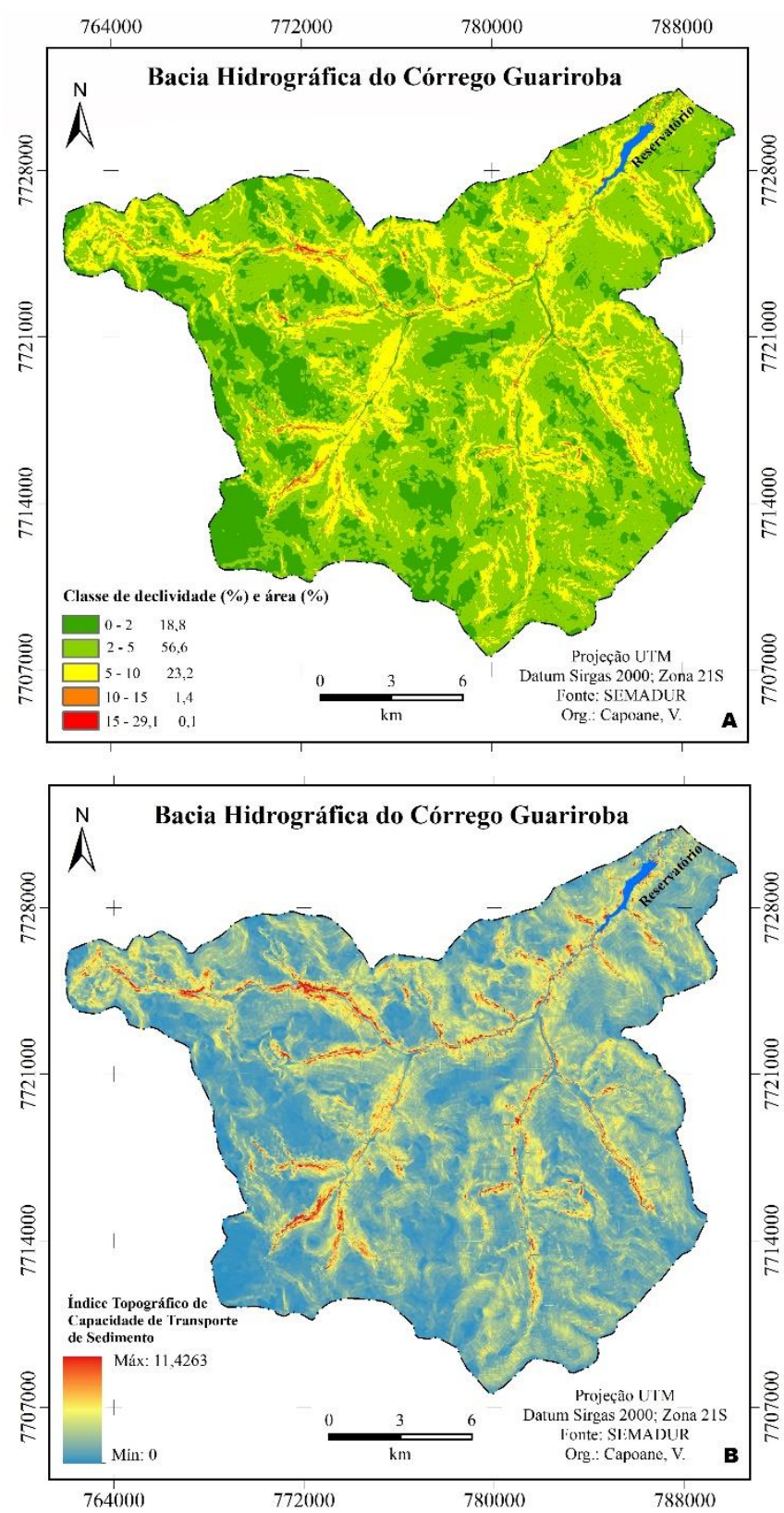

Figura 2. Classes de declividade (A) e; Índice Topográfico de Capacidade de Transporte de Sedimento (B) para a bacia hidrográfica do Córrego Guariroba.

Conforme Capoane, Costa e Kuplich (2017), embora o ITU se limite a especificar zonas com potencial de saturação hídrica e geração de escoamento superficial, o mapa gerado é útil para a identificação das áreas hidrologicamente sensíveis. Essas áreas devem receber atenção especial devido a sua propensão em gerar escoamento superficial, mesmo em condições de chuva de baixa intensidade. Elas também são áreas sensíveis aos processos erosivos, pela movimentação da água em superfície, que causam carreamento de partículas de solo. Dessa forma, os resultados encontrados podem subsidiar o manejo da área, possibilitando o planejamento sobre os locais prioritários para restauração das áreas de preservação permanente e, restrição de uso.
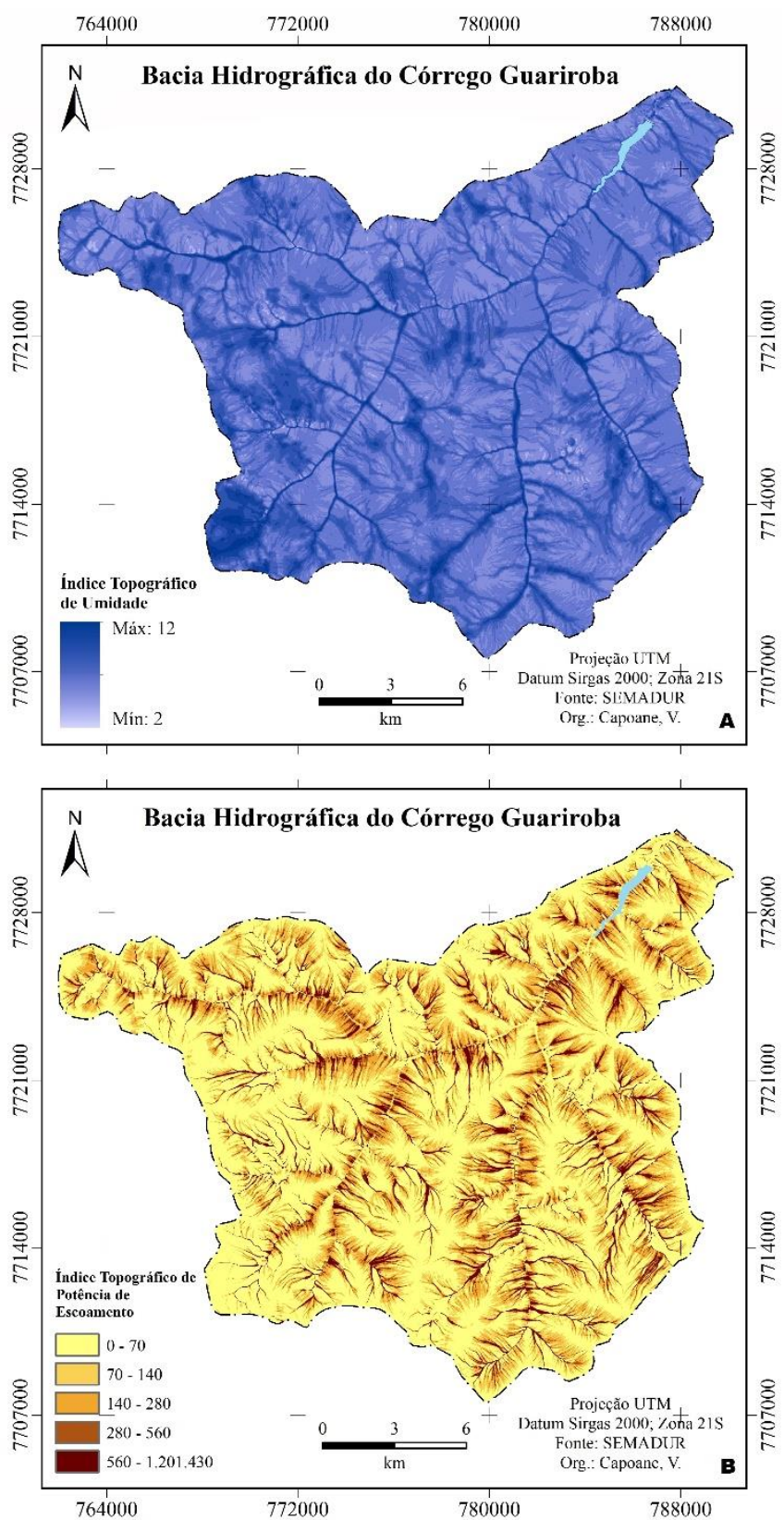

Figura 3. Índice Topográfico de Umidade (A) e; de Potência de Escoamento (B) da bacia hidrográfica do Córrego Guariroba.

O índice topográfico de potência de escoamento variou de 0 a 1.201 .430 (Figura 3B) e o desvio padrão foi de 4.556 e a média 166. Os maiores valores do ITPE correspondem às áreas declivosas com vertentes lineares, indicando locais na paisagem com maior risco de aparecimento de canais de erosão e ravinas. Os baixos valores ocorrem em áreas com relevo suave e áreas de várzeas, que resultam em baixa energia erosiva em função da redução da velocidade dos fluxos superficiais, logo, locais de menor risco de ocorrência de 
processos erosivos por fluxos concentrados.

A detecção de mudança de cobertura do solo é uma das técnicas mais importantes e amplamente utilizada para o planejamento e gerenciamento do uso da terra. Nos mapas gerados, as cores utilizadas para representação da vegetação foram azul, amarelo e verde. A cor azul, valores negativos, representa os corpos d'água; a cor amarela representa os mais baixos valores de NDVI, indicando o menor verdor e, portanto, condição crítica de vigor da vegetação ou, ausência de cobertura vegetal (solo exposto); já a cor verde-escura representa os valores mais elevados do índice de vegetação, indicando maior vigor.

Observa-se que no mês de janeiro há uma predominância de valores superiores a 0,45 (cor verde), com máximo de 0,864158 (Figura 4A), ou seja, as plantas nesse período estão no máximo vigor, reflexo do período chuvoso em Campo Grande.

Há três pontos na $\mathrm{BH}$ que apresentaram comportamento similar ao de água, quando são de solo exposto, muito provavelmente é água acumulada da chuva (NE do reservatório, centro e, $\mathrm{SO}$ da $\mathrm{BH})$. No período de inverno o valor máximo encontrado foi de 0,747459 (Figura 4B), o que se atribui a intensidade pluviométrica que começa a reduzir significativamente no mês de maio. Na Figura 4B é possível melhor observar onde encontram-se os remanescentes de vegetação nativa e, as áreas de silvicultura (representadas por formas lineares).

Em trabalho desenvolvido por Oliveira et al. (2017) sobre o uso e cobertura da terra entre 1984 e 2017 na BH do Córrego Guariroba, os autores constataram que atualmente a vegetação do bioma Cerrado representa menos de $20 \%$ da área da $\mathrm{BH}$, restrita a fragmentos isolados e trechos ao longo dos cursos d'água, e, abaixo do que preconiza o Código Florestal (Lei $n^{\circ}$ 12.651/2012). Com relação a supressão da vegetação nativa, segundo esses autores, em 1984 a região possuía 50,3\% de cobertura do bioma Cerrado e, em 2017 a vegetação florestal havia sido reduzida para 18,2\% da área da $\mathrm{BH}$ e, a maior supressão teria ocorrido durante o processo de construção da barragem para abastecimento de Campo Grande, o que teria justificado a criação da APA. Os autores também detectaram aumento significativo na atividade de silvicultura, que passou a se destacar em 2017, ocupando 8,2\% da área, ocorrendo em antigas áreas de pastagens e também em pequenas áreas de Cerrado. Essa atividade tem como consequência direta o aumento na transpiração, logo, diminuição da capacidade de armazenamento de água no solo, e diminuição da quantidade de água armazenada no reservatório Guariroba.

A Figura 5 mostra a distribuição espacial da área plantada com eucalipto nas microrregiões e municípios do MS no ano de 2017. O avanço da silvicultura vem ocorrendo em solos de baixa aptidão para agricultura, principalmente Neossolos Quartzarênicos, na Mesorregião Leste de Mato Grosso do Sul. Em 2017, cinco municípios possuíam mais de $100 \mathrm{mil}$ hectares de área plantada com eucalipto, sendo eles: Três Lagoas, Ribas do Rio Pardo, Água Clara, Brasilândia e Selvíria, com 245.000, 210.000, 126.000, 120.000 e 110.000 hectares, respectivamente (IBGE, 2019). O município de Campo Grande, onde está inserida a bacia hidrográfica do
Córrego Guariroba, está em nono lugar no ranking estadual de área plantada com eucalipto, com 24.000 ha em 2017.
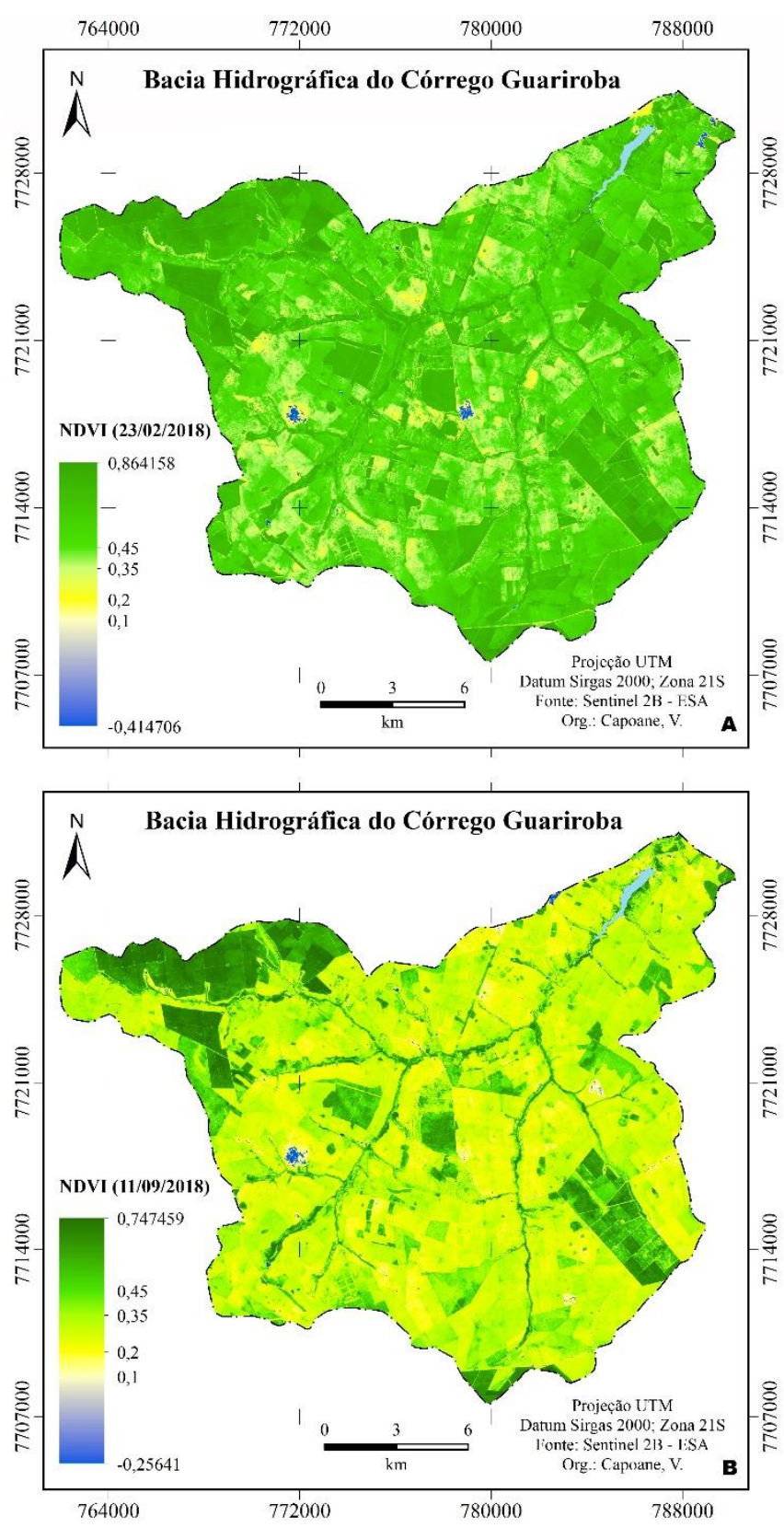

Figura 4. Índice de Vegetação por Diferença Normalizada da bacia hidrográfica do Córrego Guariroba no verão (A) e inverno (B) de 2018.

Além da conversão de sistemas naturais para pastoreio do gado e recentemente silvicultura, segundo Camargo et al. (2010), a maior parte dos proprietários não faz os manejos estabelecidos pelo programa de proteção da APA, alegando que o custo para a manutenção ecológica é elevado, em relação à renda obtida no exercício de suas atividades econômicas, inviabilizando sua aplicação. Dessa maneira, conforme esses autores, a legislação ambiental não é cumprida na maioria das propriedades, seja em relação às Áreas de Preservação Permanente e/ou de Reserva Legal, que não possuem o tamanho preconizado na Lei $n^{\circ} 12.651 / 2012$.

Outro fator identificado por Camargo et al. (2010), é a falta 
de físcalização pelo do poder público, não sendo exigido, assim, o cumprimento da legislação ambiental vigente. Para esses autores, a situação é agravada pela falta de interesse do poder público e da coletividade na divulgação da real situação apresentada na APA, tornando-se um descaso público.
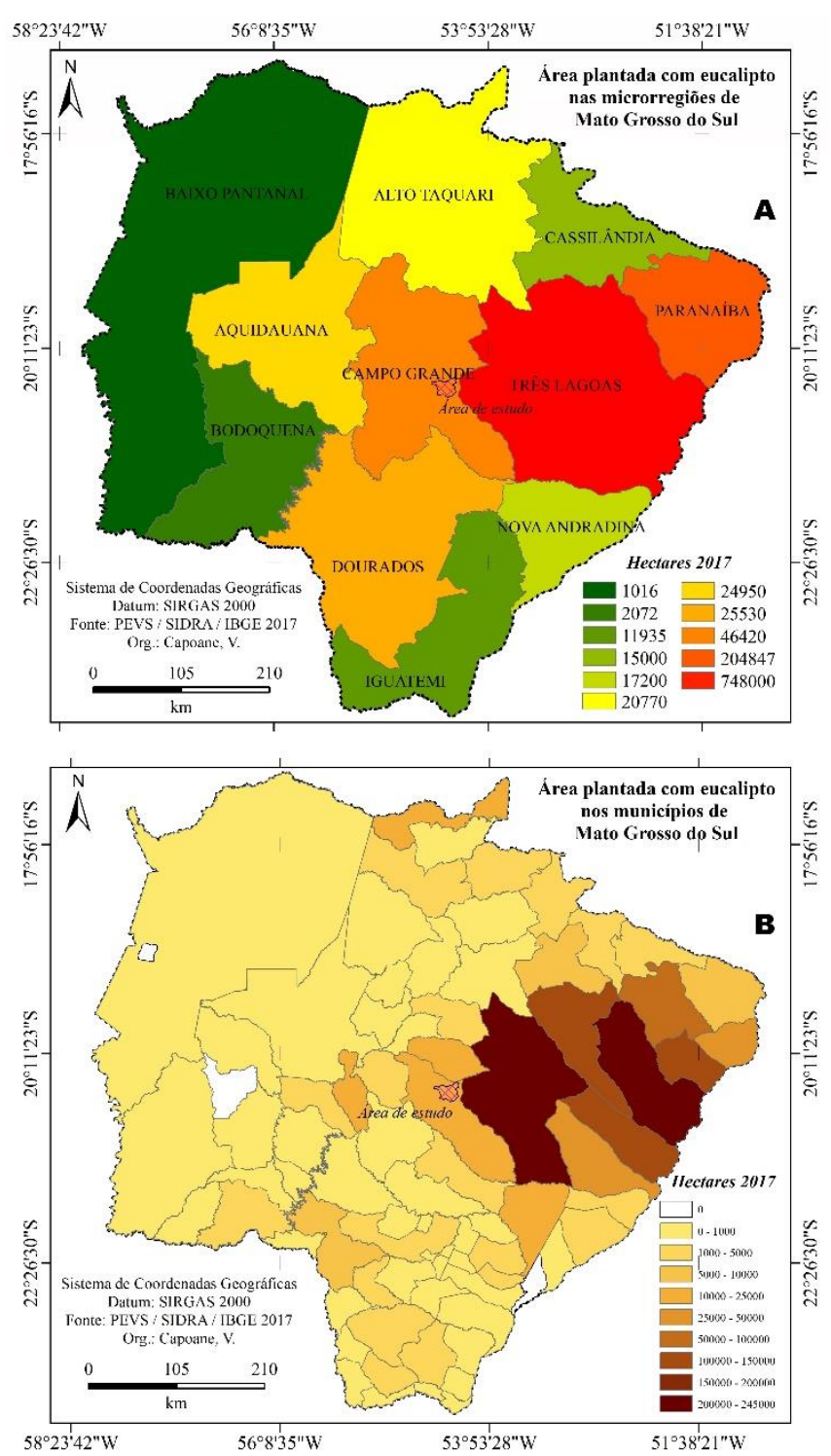

Figura 5. Área plantada (hectares) com eucalipto nas microrregiões (A) e municípios (B) do Mato Grosso do Sul em 2017. Fonte: Produção da Extração Vegetal e da Silvicultura / IBGE, 2019.

Considerando que na atualidade a cobertura vegetal da $\mathrm{BH}$ do Córrego Guariroba vem sendo alterada, principalmente através da conversão de áreas utilizadas na pecuária para silvicultura; que o manejo das atividades antrópicas é incompatível com o Plano de Manejo da APA; e que os solos da BH são altamente susceptíveis ao desenvolvimentos de processos erosivos (Neossolos Quartzarênicos), o NDVI, ITCTS, ITU e ITPE, podem ser utilizados para identificação das áreas mais sensíveis na paisagem e prioritárias para recuperação, a fim de preservar a água em termos qualitativos e quantitativos, pois este manancial é a fonte de $36 \%$ da água que abastece Campo
Grande.

\section{Conclusões}

Os atributos topográficos permitiram a identificação dos locais mais susceptíveis ao desenvolvimento dos processos erosivos, que, encontram-se ao longo dos cursos d'água, nas cabeceiras de drenagem e em vertentes côncavas convergentes. Esses locais constituem áreas prioritárias para recuperação ambiental. Os remanescentes florestais de Cerrado encontramse em trechos ao longo dos cursos d'água e, em fragmentos. Observou-se a inserção da atividade de silvicultura, que tem como consequência direta a diminuição da capacidade de armazenamento de água no solo em função da transpiração.

Os atributos topográficos primários e secundários e o NDVI gerados no presente trabalho constituem ferramentas a serem utilizadas pelos gestores, uma vez que, possibilitam a definição das áreas prioritárias para a recuperação e restrição de uso, a fim de proteger o reservatório tanto em termos qualitativos quanto quantitativos, pois este manancial é a principal fonte de água superficial que abastece a cidade de Campo Grande.

\section{Referências}

Alvares, C.A., Stape, J.L., Sentelhas, P.C., Gonçalves, J.L.M., \& Sparovek, G. (2013). Köppen's climate classification map for Brazil. Meteorologische Zeitschrift, 22(6), 711-728. doi: http://dx.doi.org/10.1127/09412948/2013/0507

Araújo, H.J.T., Santos Neto, A., Trindade, C.A.H., \& Pinto, J.C.A., Montalvão, R.M.G., Dourado, T.D.C., Barros, R.C., Colombo, P., Tassinari, C.G. (1982). Geologia. In.: Projeto RADAMBRASIL - Folha SF-21 - Campo Grande. RADAMBRASIL, Rio de Janeiro, Brasil 28, 9-124.

Brasil. (2003). Lei $\mathrm{n}^{\circ} 9.985$, de 18 de julho de 2000; Decreto $\mathrm{n}^{\circ} 4.340$, de 22 de agosto de 2002. Sistema Nacional de Unidade de Conservação da Natureza - SNUC: 3. ed. aum. Brasília: MMA/SBF, pp. 52.

Burt. T.P., \& Butcher, D.P. (1935). The role of topography in controlling soil moisture distributions. Journal of Soil Science, 36, 469-486. doi: http://dx.doi.org/10.1002/esp.3290030402

Camargo, C.M.J., Camargo, L.J.J., \& Oliveira, A.K.M. (2010). Efeitos da legislação ambiental na proteção da Área de Proteção Ambiental do Guariroba, Mato Grosso do Sul. Revista Uniara, 13(1), 115-124. Recuperado http://www.periodicos.rc.biblioteca.unesp.br/index.php/estgeo/article/vie w/10926

Capoane, V., Costa, L.F.F., \& Kuplich, T.M. (2017). Efeito da resolução de modelos digitais de elevação na derivação do índice topográfico de umidade: estudo de caso no município de Palmitinho-RS. Geografia em Questão, 10, 9-23. Recuperado de http://erevista.unioeste.br/index.php/geoemquestao/article/view/15134

Capoane, V. (2015). Determinação do índice de potência de escoamento para o município de Palmitinho/RS utilizando modelos digitais de elevação. Estudos Geográficos (UNESP), 13, 106-117.

Centro de Monitoramento do Tempo e Clima - CEMTEC/MS. Banco de Dados. Recuperado de http://www.cemtec.ms.gov.br/boletinsmeteorologicos/

Conrad, O., Bechtel, B., Bock, M., Dietrich, H., Fischer, E., Gerlitz, L., Wehberg, J., Wichmann, V. e Boehner, J. (2015). System for Automated Geoscientific Analyses (SAGA) v. 2.1.4. Geoscientific Model Development, 8, 1991-2007. doi: https://doi.org/10.5194/gmd-8-19912015

Environment Agency - EA UK. (2013). Impact of Climate Change on Dams \& Reservoirs. Recuperado de http://evidence.environmentagency.gov.uk/FCERM/Libraries/FCERM_Project_Documents/FD2628 _final_report.sflb.ashx.

Hooke, R.L., Martín-Duque, J.F., \& Pedraza, J. (2012). Land transformation by humans: A review. GSA Today, 12(12), 4-10. doi: https://doi.org/10.1130/gsat151a.1 
Hutchinson, M.F. (1989). A new procedure for gridding elevation and stream line data with automatic removal of spurious pits. Journal of Hydrology, 106(3-4), 211-232. doi: https://doi.org/10.1016/0022-1694(89)900735337

Instituto Brasileiro de Geografia e Estatística - IBGE (2019). Produção da Extração Vegetal e da Silvicultura, 2017. Recuperado de https://sidra.ibge.gov.br/pesquisa/pevs/quadros/brasil/2017

Jenson S.K., \& Domingue, J.O. (1988). Extracting Topographic Structure from Digital Elevation Data for Geographic Information System Analysis. Photogrammetric Engineering and Remote Sensing, 54(11), 1593-1600.

Lepsch, I.F. (Coord.). (1991). Manual para levantamento utilitário do meio físico e classificação de terras no sistema de capacidade de uso. $\left(4^{\mathrm{a}}\right.$ aproximação, pp. 175). Campinas: Sociedade Brasileira de Ciência do Solo.

Minella, J.P.G., Merten, G.H., \& Ruhoff, A.L. (2010). Utilização de métodos de representação espacial para cálculo do fator topográfico na equação universal de perda de solo revisada em bacias hidrográficas. Revista Brasileira de Ciência do Solo, 34, 1455-1462. doi: http://dx.doi.org/10.1590/S0100-068320100004000412010

Oliveira, A.K., Fernandes, V., Pirajá, R.V., \& Silva, M.H.S. (2017). Avaliação multitemporal das paisagens da Área De Proteção Ambiental (APA) dos mananciais do córrego Guariroba, Campo Grande, Mato Grosso do Sul, por meio de imagens de satélites. Ra'e Ga, 42, 8-20. doi: http://dx.doi.org/10.5380/raega.v42i0.43753911

Schlanger, Z. (2018). Dams and reservoirs can't save us. This is the new future of water infrastructure. https://qz.com/1353828/dams-andreservoirs-cant-save-us-this-is-the-new-future-of-water-infrastructure/

Secretaria Municipal de Meio Ambiente e Desenvolvimento Urbano SEMADUR. (2008). Plano de Manejo da Área de Proteção Ambiental dos Mananciais do Córrego Guariroba - APA do Guariroba. Recuperado de http://www.campogrande.ms.gov.br/semadur/wpcontent/uploads/sites/24/2018/05/Plano-de-Manejo-APA-Guariroba2008.pdf

Silva, J.A. (2010). Direito Ambiental Constitucional. (8. ${ }^{a}$ ed, pp. 351). São Paulo, Malheiros.

Wilson, J.P., \& Gallant, J.C. (2000). Digital Terrain Analysis. In: WILSON, J.P. \& GALLANT, J.C. (Eds.). Terrain Analysis: Principles and Applications. (pp. 1-27). New York: John Wiley and Sons, Inc.

\section{Licença Creative Commons CC BY 4.0}

Este artigo foi publicado com acesso aberto para distribuíção sob os termos do Licença de Atribuição Creative Commons, que permite uso irrestrito, distribuição, e reprodução em qualquer meio, desde que o trabalho original seja devidamente citado. 